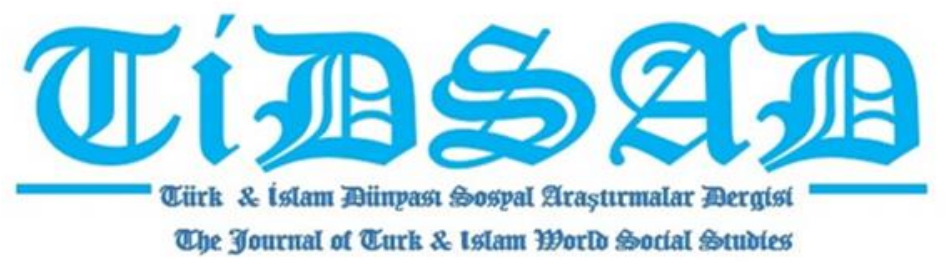

Yıl: 7, Sayı: 25, Haziran 2020, s. 262-274

Ala ELHiLAL

elhilalala1@gmail.com

\title{
İBN ḤAZM EL-ENDELUSÎ VE ṬAVḲU-'L ḤAMÂME Fİ'L İLFETİ VE'L-ÜLLÂF EDLI ESERİ ANALİZI
}

\section{Özet}

Endülüs medeniyetinin en önemli şahsiyetlerinden olan İbn. Hazm'ın ilmî kişiliğine denk edebî bir kişiliği de vardır. Fıkıh, hadiş, dinler tarihi, mezhepler tarihi, felsefe, mantık ve soybilimi alanlarında seçkin bir âlim, güçlü bir cedelci ve büyük bir düşünür olarak meşhur olduğu kadar; edip, eleştirmen ve soylu bir şair olarak da meşhurdur. Sanat inceliğiyle düşünce gücünü bir arada toplayan nadir şahsiyetlerdendir. Bu çalışma ibn. Hazm'ın Ṭavḳu' L-Ḥamâme fi 'L-İlfeti ve' L Üllâf adlı eserinin bilimsel yönden incelenmesidir. İbn. Hazım en tanınmış alimlerinden biri olup Batılılar onu daha çok karışlaştırmalı din alanında tanımışlardır. $\mathrm{Bu}$ konuyu, ibn. Ḩazm'ın çalışmalarının tanıtımına katkında bulunmak amaçıyla seçtik İki bölümden oluşan çalışmanın birinci bölümunde ibn . Ḥazm döneminde Endülüs'ün siyasi, sosyal ve ekonomik yapısı kısaca tanıtılmış ve ibn. Ḥazm 'ın hayatı, edebi yönü, hocaları, çalışmaları ve talebeleri hakkında bilgi verilmiştir. İkinci bölümde ise Ṭavḳu' L -Ḥamâme adlı eseri ele alınmış, eserin yazılma nedeni , konuları, dil ve metodu , Endülüs edebiyatı içindeki yeri üzerinde durulmuştur ve tanitılmıştır.

Anahtar Kelimeler:İbn Hazım, Ṭavḳu' L-Ḥamâme, Endülüs

\section{ANALYSIS OF İBN HAZM AL ANDALOUSY AND HIS MASTERPIECE TAOUK AL HAMAMA FIL ULFATY WAL ULLAF .}

\begin{abstract}
Ibn-Hazm is one of the most important figures of the Andalusian civilization. He also has a literary personality equivalent to his scientific personality. As much as he was famous as a distinguished scholar, a powerful critic and great thinker in the fields of fiqh, hadith, the history of religions, the history of sects, philosophy, logic and genealogy; he was also famous as a critic and noble poet. He is one of the rare
\end{abstract}


figures that combines the delicacy of art and power of thought.. This essay is considered a scientific study of ibn.Hazm 's masterpiece Tavku'l Hamame fil ülfeti vel üllef ,He is one of the most prominent scientists of Andalusia and the western scientists knew him mainly in the domain of comparative religion. We decided to choose this topic mainly because ibn Hazm's works haven't been given the value they deserve and not enough definitions have been made about him. This essay consists of two parts and in the first part a prief description is made about Andalusia's political, Economic, and social construction, and some information is given about his life, literature, Teachers and apprentices. The second part deals with why Tavku '1 Hamame was written ,it's subjects language \& method ,and at last andalusian literature is defined.

Keywords:ibn Hazm, Tavku'l Hamame, Andalus

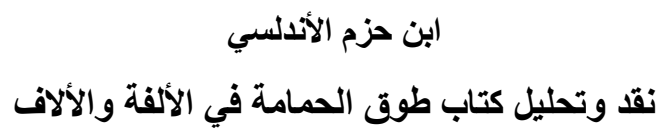

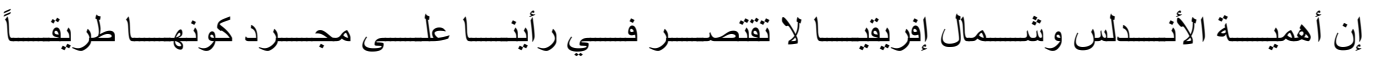

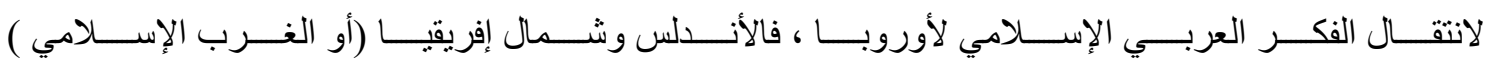

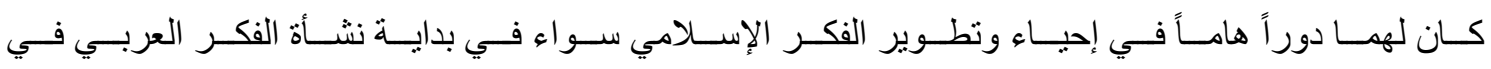
الغرب الإسلامي أو في المشرق الإسلامي .

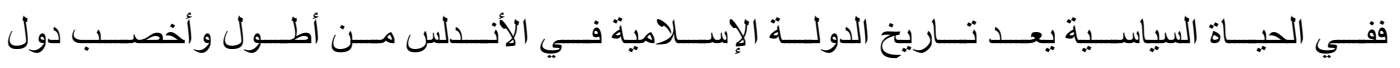

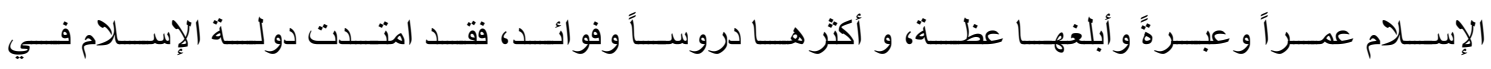

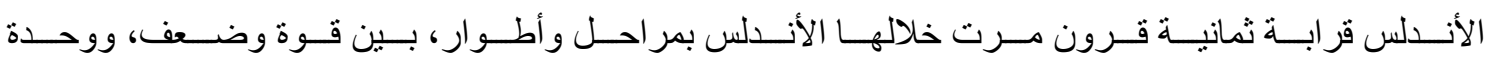

عبد الرحمن الحجي، التاريخ الأندلسي من الفتح الإسلامي حتى سقوط غرناطة، ط3 ،دار القلم، دمشق, , 1987,ص147 
التعريف بابن حزم

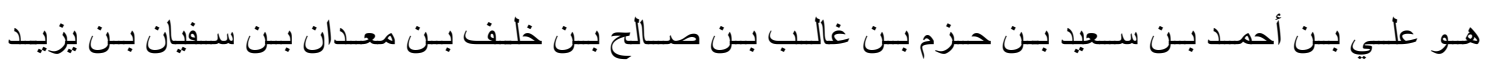
مولى .2. هو أول من دخل المغرب منهم.

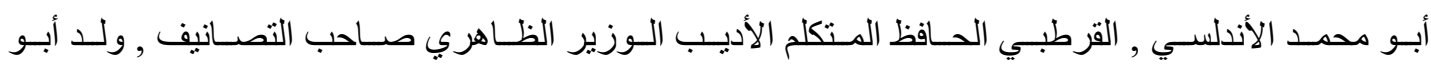

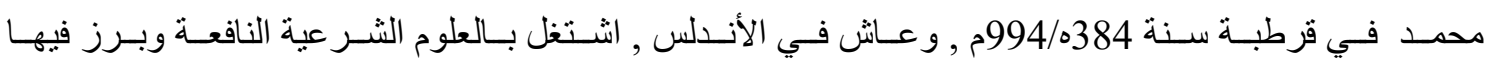
وفاق أهل زمانه وصنف الكتب المشهورة3.3.

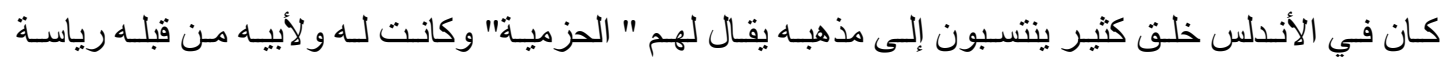

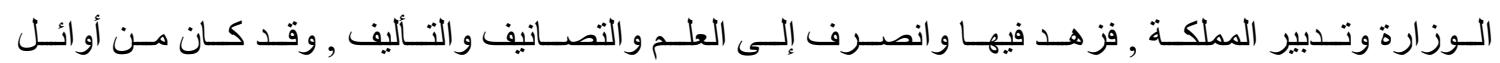
الباحثين فقيهاً حافظاً يستنبط الأحكام من الكتاب و السنة. 4

نسبه: اختلفت أقوال العلماء و الفقهاء في نسب ابن حزم الأندلسي ـرحمه اللهـ على قولين رئيسين:

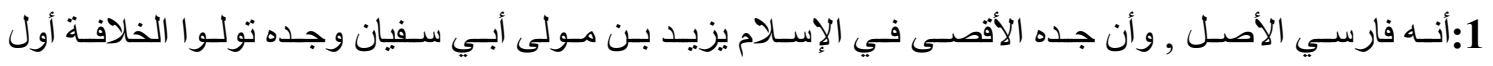
ما دخل الأندلس.

2: أنه أندلسي الأصل وقد قال بعض المستشرقين بذلك مثل رينهارت دوزي ,وجولد تسيهر وبروكلمان و غير هم.

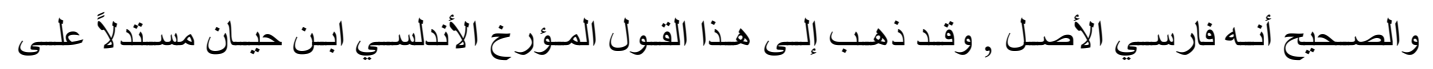

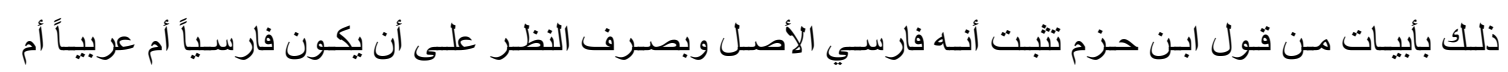

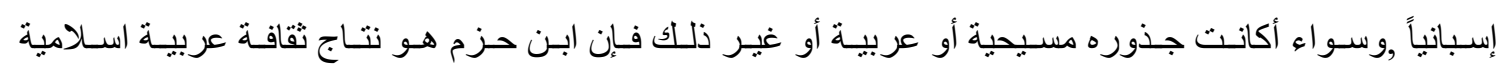

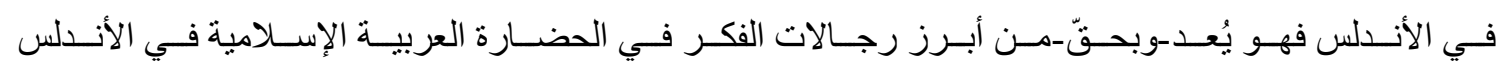

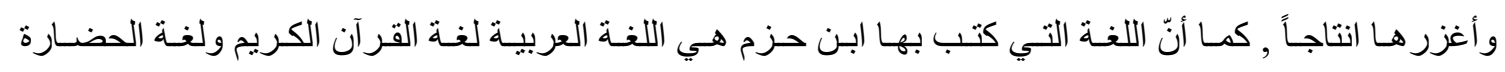

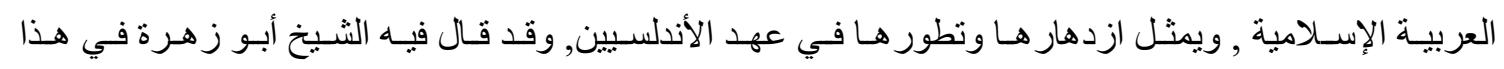
الثيء " علا ابن حزم بعلمه ولم بعلُ بنسبه"5.

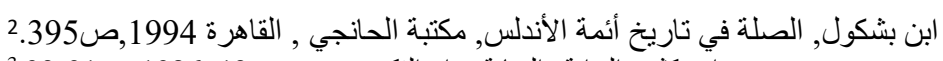

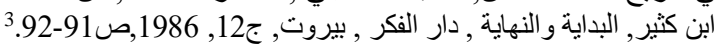

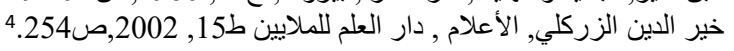

محمد أحمد أبو زهرة ,الإمام ابن حزم حياته وعصره وآراؤه وفقها, دار الفكر العربي , القاهرة , 1425ه, ص205
} 
-نشأتها:

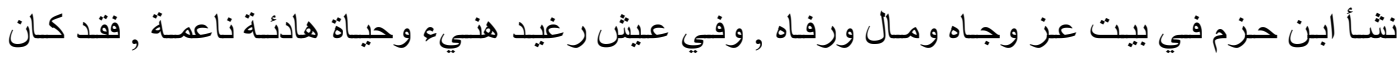

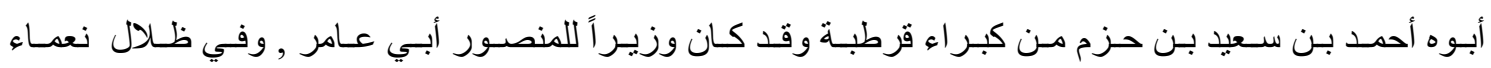





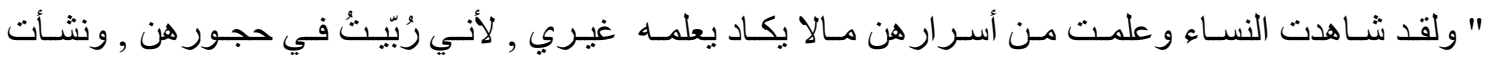
بـين أيـديهن ولـم أعـرف غيـر هن .......................

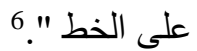

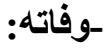

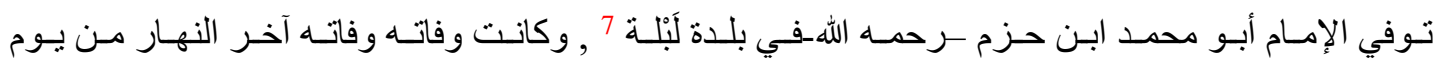
الأحد لليلتين بقيتا من شهر شعبان سنة 456ه , وكان عمره آنذاك اثنتين وسبعين إلا شهراً.

شيوخه وتلاميذه

تتلمذ ابن حزم على يد عدد كبير من العلماء , فأخذ عن بعضهم علوماً كثيرةً ولعل أهم و أبرز من أخذ عنهم ابن حزم هو أبو علي الحسين بن علي الفاسي الذي قال فيه " ما رأيت مثله جملة علماً وعملاً , وديناً وور عاً, و ونفعني به الله كثير اً, و وعلت موقع الإساءة , وقبح المعاصي "'. ومن أشهر الذين تتلمذ على أيديهج: - 20 * _أبو القاسم عبد الرحمن بن أبي يزيد الأزدي فقد أخذ عنه النحو و الحديث و الفقه واللغة والكلام.

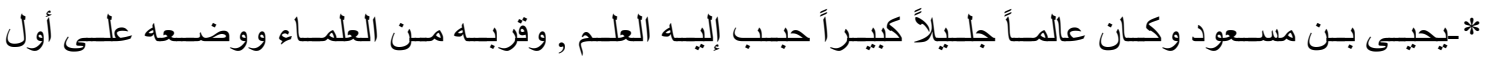
الطريق. * - حسان بن مالك بن أبي عبده الوزير من الأئمة في اللغة والأدب 10 * - عبدالله بن يحيى بن أحمد , و هو أستاذ ابن حزم في الفقه . * أبو الخيار - مسعود بن سلمان مفلت - وقد تلقى على يديه أصول الفقه الظاهري .

\footnotetext{
ابن حزم الاندلسي , طوق الحمامة في الألفة والألاف, تح د. احسان عباس ,المؤسسة العربية للارسات والنشر , بيروت , لبنان ,ط2 6. 166,1987,

انظر : ياقوت الحموي , معجم لبلة: مدينة قديمة غربي الأنلس , وهي من الددن القيمة الكبرى تقع غربي إثبيلية وقرطبة في إسبانيا7

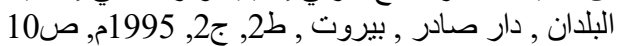

علي بن بسام الثنتريني , الذخيرة في محاسن أهل الجزيرة , تحقيق د. إحسان عباس , الدار العربية للكتاب , ليبيا , تونس , ج1, ط1, 8

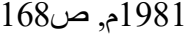

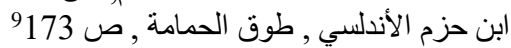

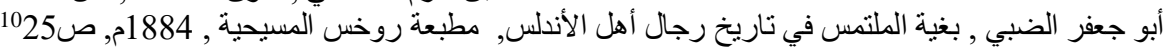




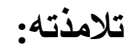

لـم تـــكر كتـب التـر اجم عـداً كبيـراً مـن نلامـذة ابـن حـزم , ويعـود السـبب في ذلـك لتحـريض علمـاء

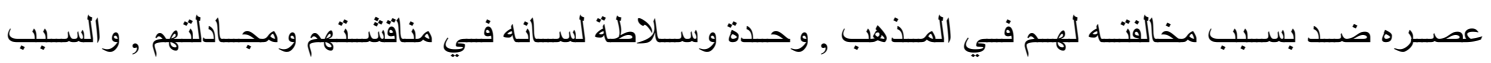

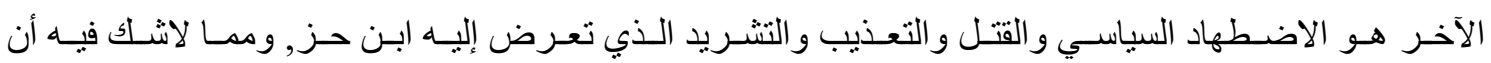



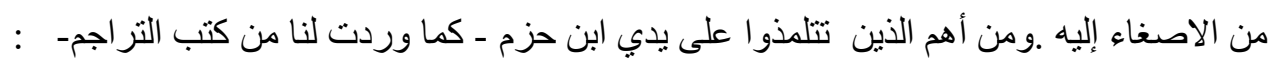
* ـ أبو عبدالله محمد بن أبي نصر فتوح بن عبدالله الحمبدي

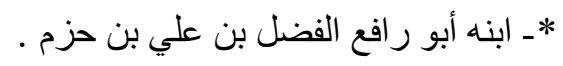
* مؤلفات ابن حزم

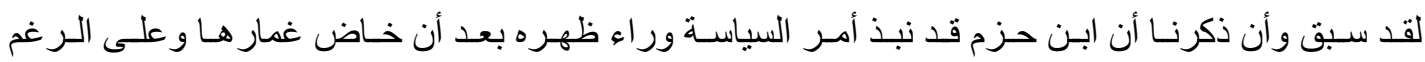

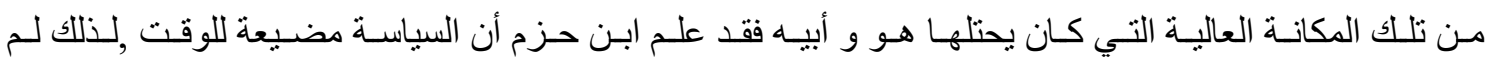

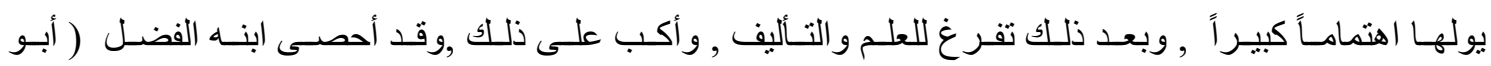

مؤلفات أبيه فإذ هي قرابة أربعمائة مجلد في ثمانين ألف ورقة , هذا مع جودة مصنفاته.11

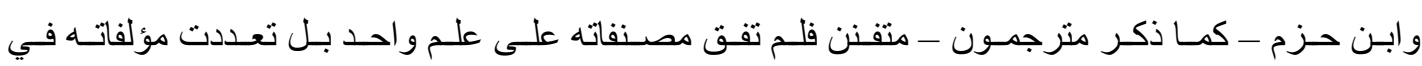

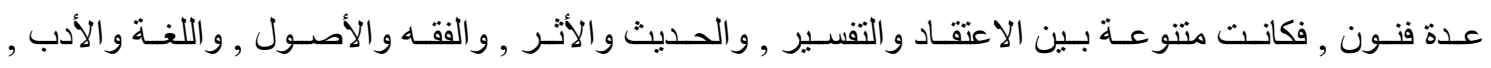

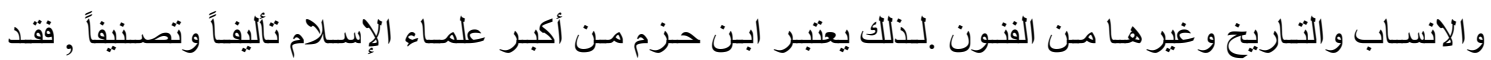
خلف ور اءه مكتبة موسو عية ضخمة , وثقافة كبيرة , ضمت مجلداتها كافة أنواع العلوم . ويعـد ابـن حـزم مـن كبـار رجـال الجـدل المشـهورين بمناقتشـاتهم الجدليــة ومســاجلاتهم الكلاميـة مـع أهـل



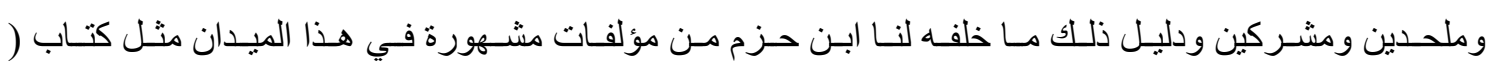

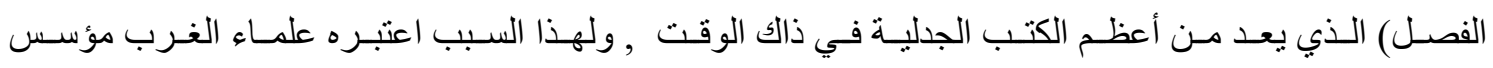
علم مقارنة الأديان. وسوف أذكر هنا أشهر مؤلفات ابن حزم المطبوع منها : 1. n البيان عن حقيقة الإيمان

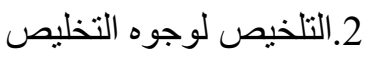
3.حكم من قال أن أرواح أهل الثقاء معذبة إلى يوم الدين

الدقري التلمساني ,نفح الطيب في غصن الاندلس الرطيب , تحقيق يوسف البقاعي , ط1, دار الفكر , بيروت 1998م, ج2, ص 239 
4.الرسالة الباهرة في الرد على أهل الأهو اء الفاسدة 5. 5 - 5 المفاضلة بين الصحابة 6.كتاب الجامع في كتابه المحلى 7.نجاسة الكلب

8..المحلّى بالآثار في شرح المجلّى :وهذا الكتاب من أشهر كتبه , فإذا ورد اسم ابن حزم ارتبط اسمه بالمحلى 9.أسماء الخلفاء المهديين والأئمة , أمر اء المؤمنين و أسماء الولاة 10.أمهات الخلفاء 11.جمل فتوح الإسلام 12. جمهرة أنساب العرب 13.طوق الحمامة في الألفة والألاف : وهو كتاب فلسفة الحب و المحبين في التحليل النفسي و الأدب .



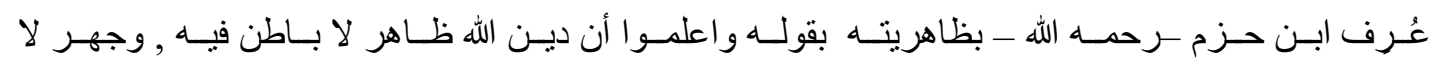

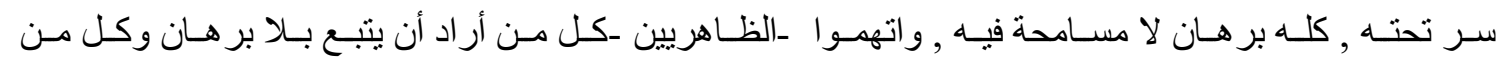

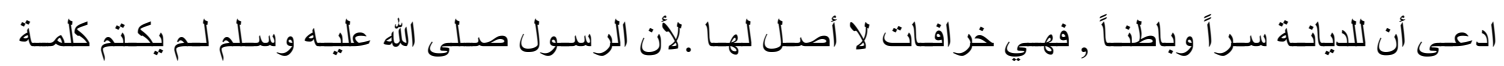
و لا كان عنده رمزاً ولا باطناً. وقد كـان الـدافع الرئيسـي لتبنـي ابـن حـزم هـذا المـذهب الظــاهري هـو انحـر اف عـدد مـن العلمـاء و الفقهـاء



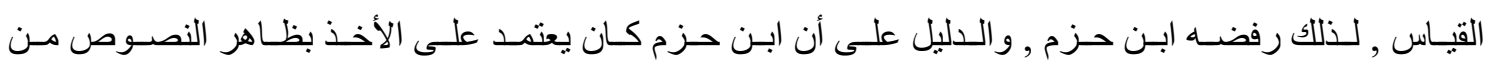
الكتاب والسنة وما أجمع عليه المسلمون هو قوله:

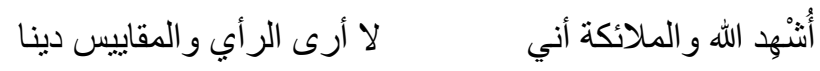

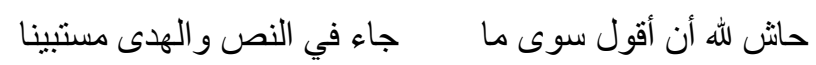

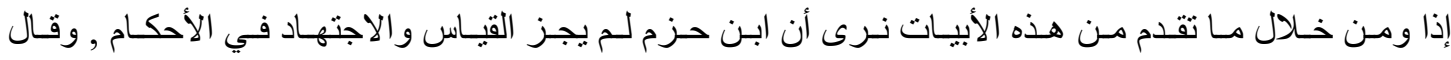

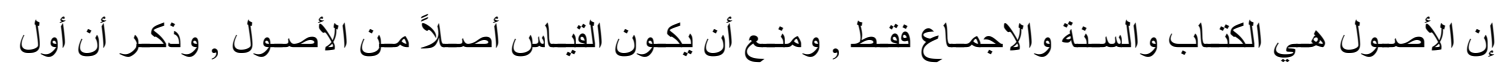
من استخدم القياس هو إبليس , وظن أن القياس خارج عن مضمون الكتاب والسنة. 


\section{نقا وتحليل كتابه طوق الحمامة في الألفة والألاف:}

- التعريف بالكتاب هو كتاب في التحليل النفسي و في شبكة العلاقات الإنسانية التي تظهر بين البشر. الألفة لغةً : الأليف.

الألاف : جمع آلف , وفلان قد ألِف هذا الموضع ( بالكسر) يألفه إلفاً 12 الألفة اصلاحاً : هو اجتماع مع التئام مع محبة. وقال التهانوي : الألفة هي ميلان القلب إلى المألوف.

وقال الجرجاني : الألفة : اتفاق الآراء في المعاونة على تدبير المعاش13 وقـد أسـماه طـوق الحمامـة إثــارة إلـى الطـوق مـن الـريش حـول عنـق بعض الحمـام، وهـو إثــارة إلـى السـلام

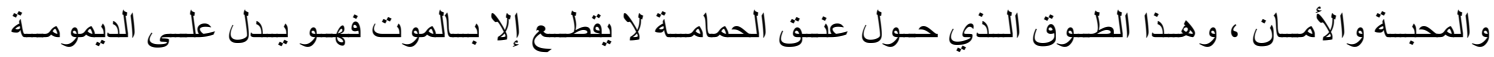
و الثبـات وكذللك هـو حسال المحبين فإنـه يتشـكل بينهمـا طوق مـن الحب فـلا ينقطع و لا ينفصـلان عن بعضـهما الـبعض إلا بـالموت ومفارقـة الـروح. ور أى أن الحمامـة هـي رسـول الحـب و الهـوى بـين العانـقين، و الطـوق

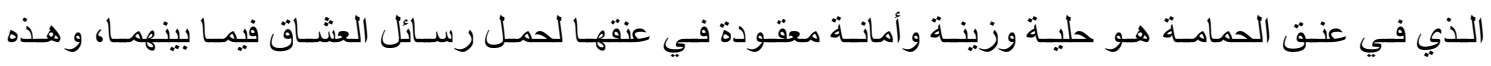
الحالة هي الحالة التي تشكلها الحمامة في تاريخ الثعر العربي.

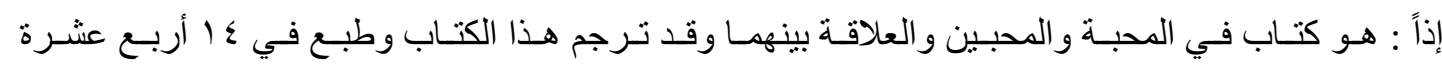

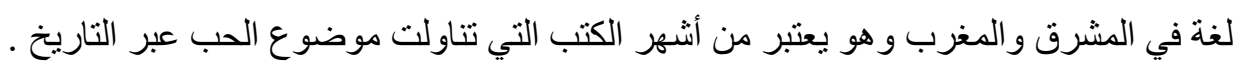
ولـه أهميـة كبيـرة في عدة أمور فهو أول مـن درس الحب دراسـة علميـة نفسية تحليليـة عميقـة ودرس معانيـه

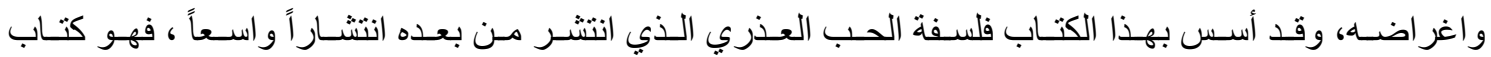
فريد من نوعه ومميز جداً.

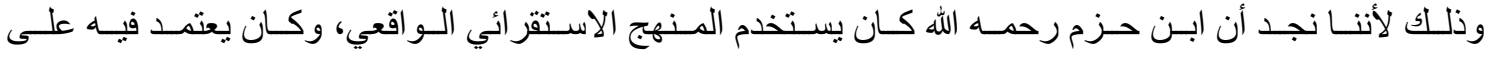

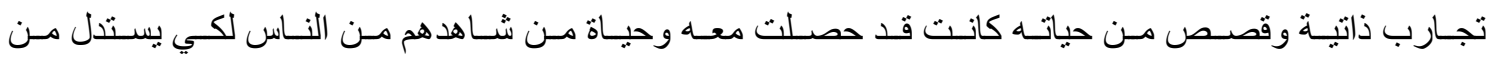
خلالها على وقائع وأحداث و هذا هو منهج العلماء في القرنين العشرين و الحادي و العشرين. - أسباب تأليف الكتاب

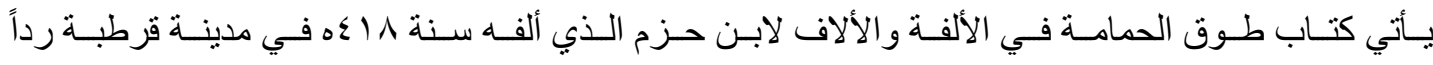

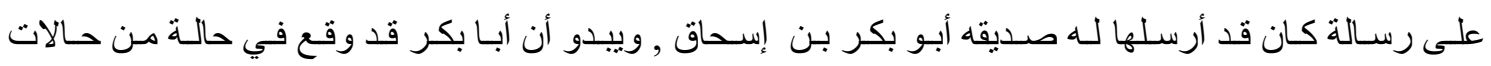

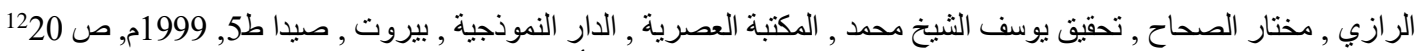

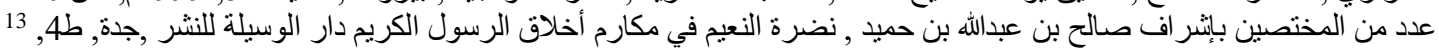

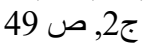




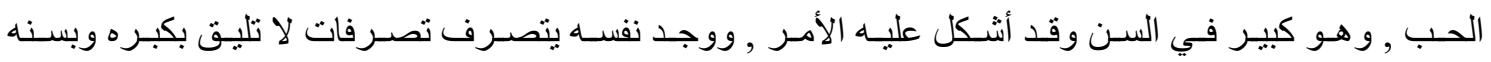

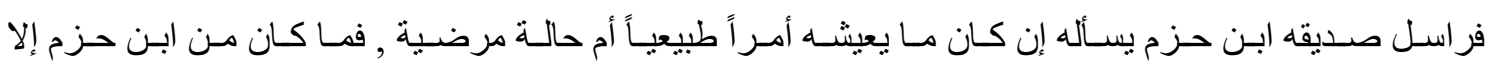

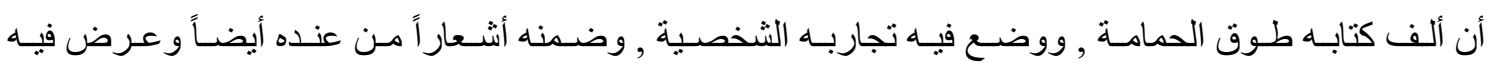

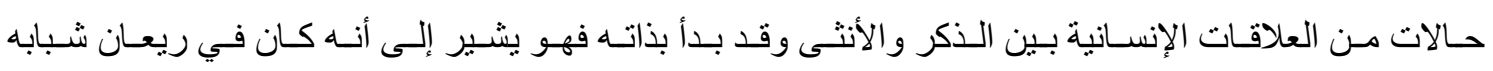

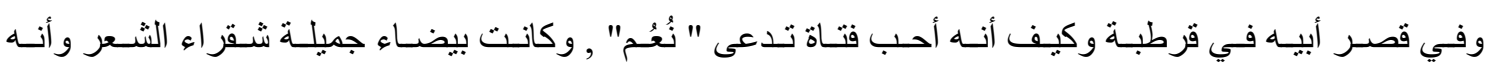

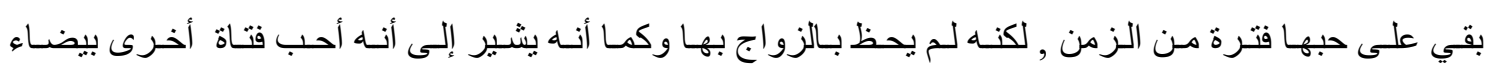


- مضمون وأبواب الكتاب



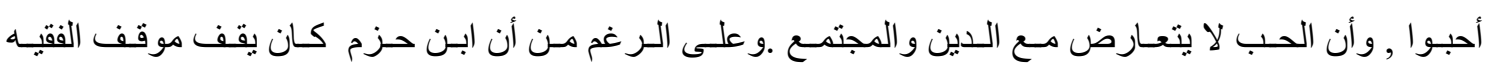

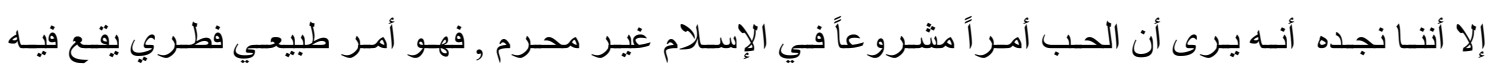
كل إنسان سو اء أكان ذكرا أم أنثى , ويرى أن الحب ليس خطر اً لا على حاكم و لا على محكوم .

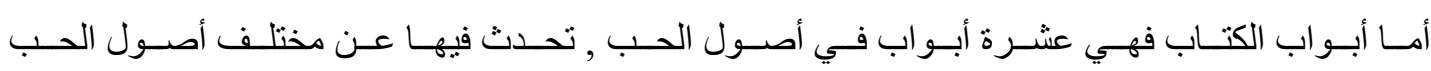

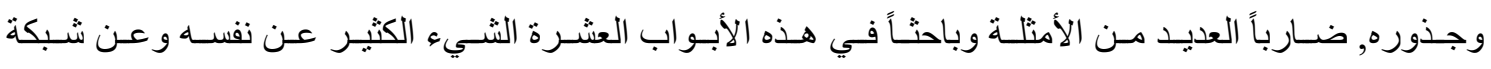

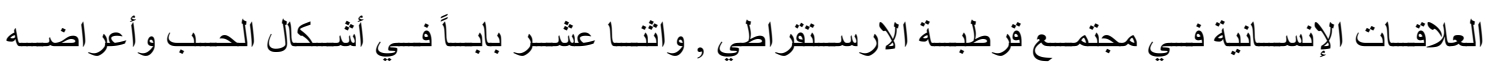



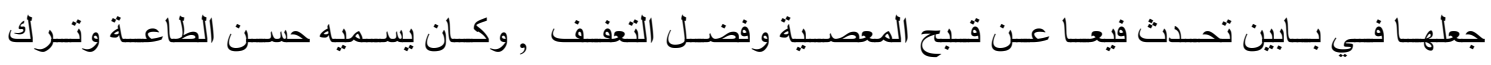

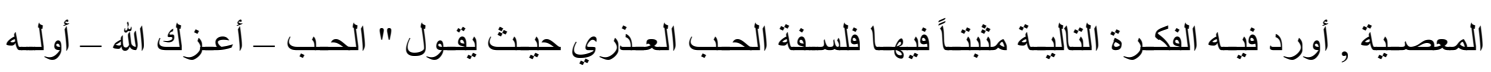



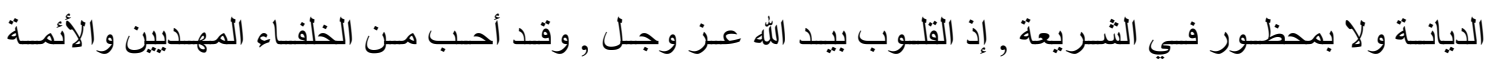

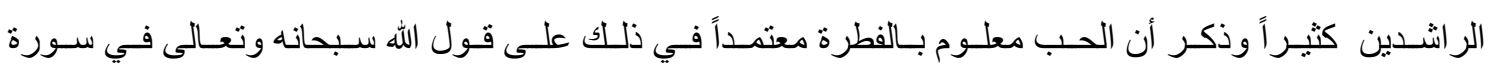
الروم "ومن آياته أنه خلق لكم من أنفسكم أزواجاً لتسكنوا إليها وجعل بينكم مودة ورحمة "14 ائه

$$
\begin{aligned}
& \text { ومن الأبواب التي ذكر ها في كتابه : } \\
& \text { *باب علامات الحب : }
\end{aligned}
$$

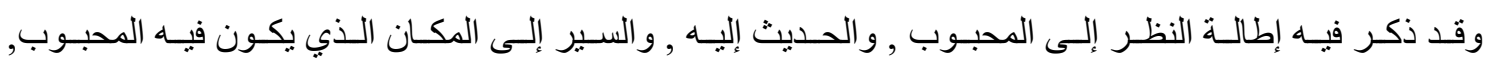

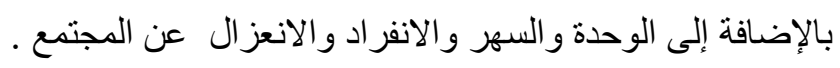

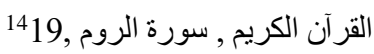




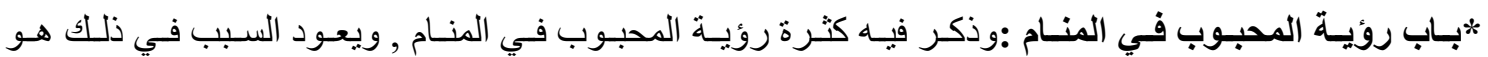
كثرة التفكير في المحبوب في النهار, فقد تقع المحبة لمجرد سماع صوت المحبوب من وراء جدار ـ *باب من أحب من نظرة واحدة: وذكر فيه وقوع الحب في لقب لمجرد نظرة من إحدى الحبيين. *بـاب الإثـارة بـالعين : وذكـر فيـهـ إنــار ات المحبـوب لمحبوبـهـ بـالعين , فالإثـارة بمـؤخرة العـين الواحـدة

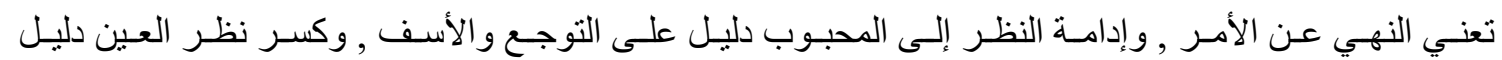
على الفرح , و الإشارة الخفية بمؤخرة العين تعني السؤال . *بـاب المراســة : وذكـر فيـهـ المر اسـلة بالرسـائل, وصـفات الرسـائل بـين المحبـين وشـور المحـب بالسـرور عند تلقيه أية رسالة من محبوبه . *باب السفير : وذكر فيه صفات الوسيط بين المحب ومحبوبه , كالكتمان و الوفاء للعهد والنصح. *باب العاذل : ذكر في هذا الباب اللوم الذي يقع عليه من قبل الآخرين وخاصة الأصدقاء. *باب الوصل : ذكر فيه وصل المحبوب لحبيبه, و المو اعبد بينهما , وانتظار الوعد من المحب.

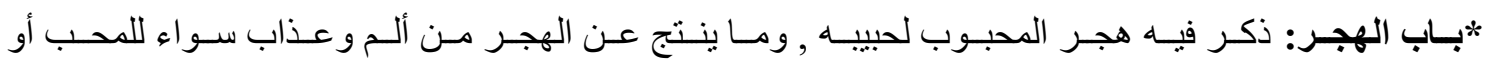
للمحبوب.

*باب الغذر : وذكر فيه أن الوفاء من نبيل الصفات , وأن الغدر من أكره الصفات و أذمها .

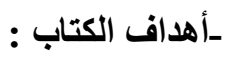

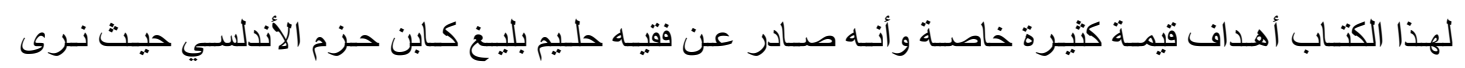

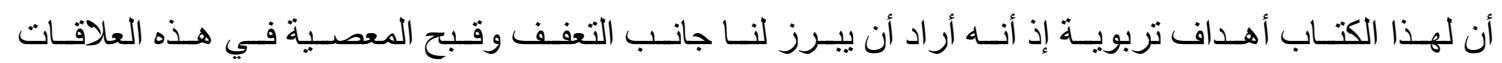

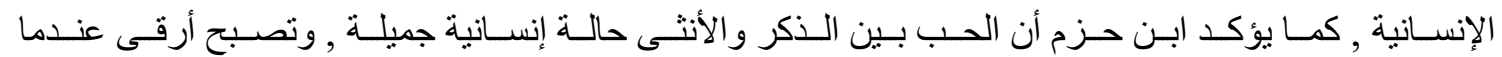
تتوج هذه العلاقات بالزواج بين العاشقين , و هي تتدرج ضمن القيم الاجتماعية و الأخلاق .

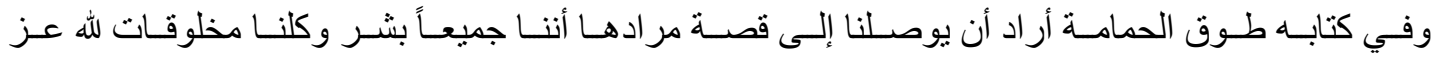

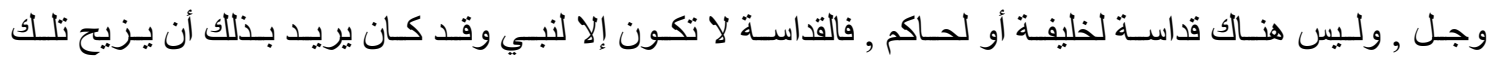
القداسة عن رجال بعينهم نحن أوصلناهم إلى القداسة بأنفسنا .

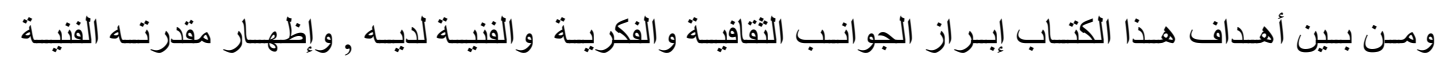

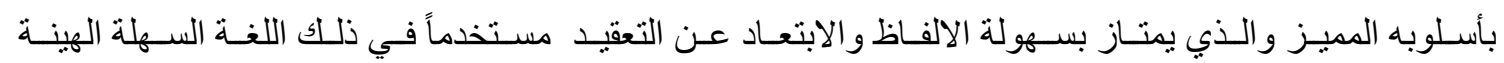

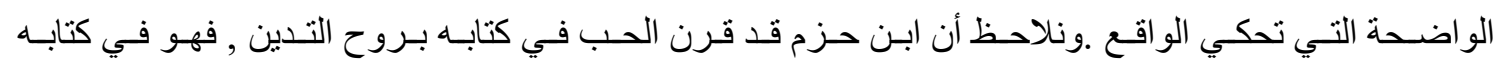
يصف ما يصفه , ويتحدث عما يتحدث عنه لكنه يهدف إلى غاية تربوية تهذيبية . 
إذاً هـو كتـاب أخلاقي مـن الدرجـة الأولى يوضـح بين مـا هـو ممنـوع ومـا هـو مسـوح , وبين الفرق بـين

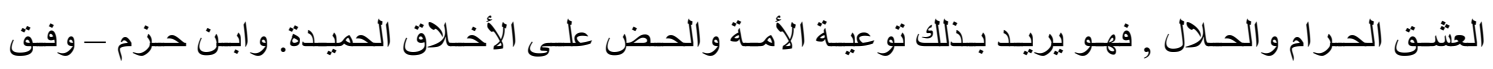

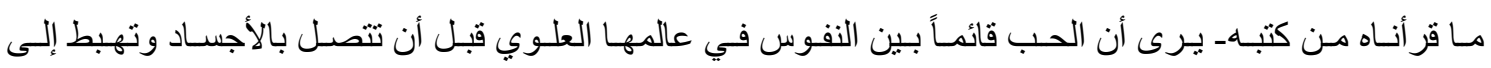

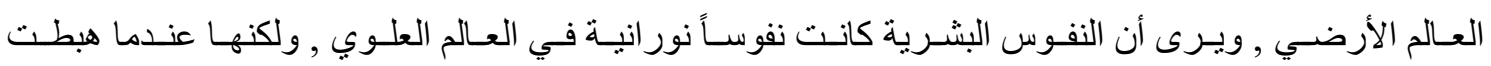

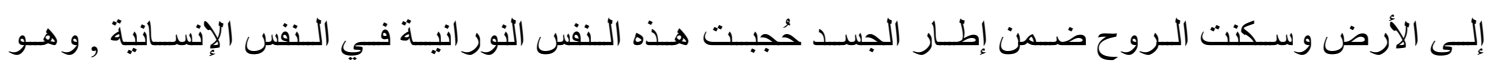

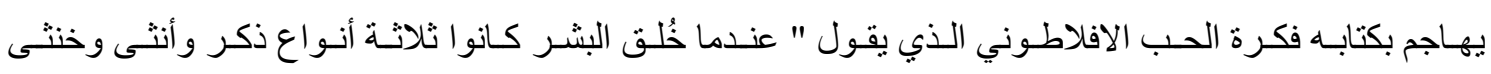

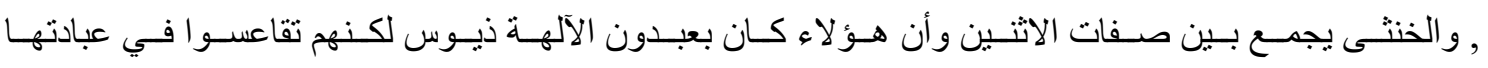



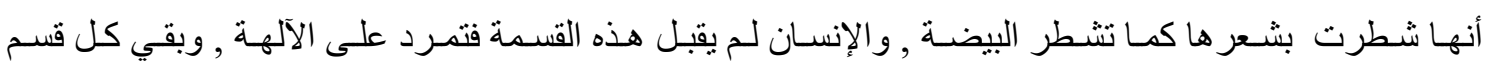

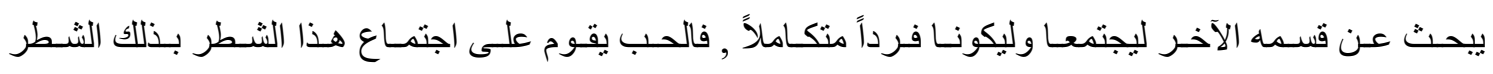

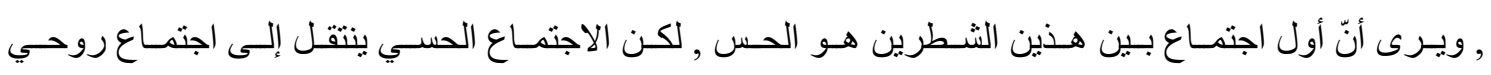
نفسي , ومن ثم ينتقل إلى حب عقلي ( هذه هي فكرة الحب الأفلاطوني ).

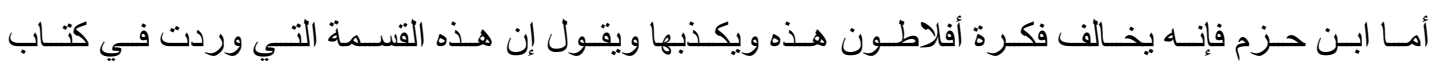

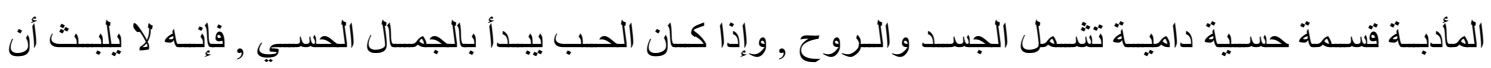

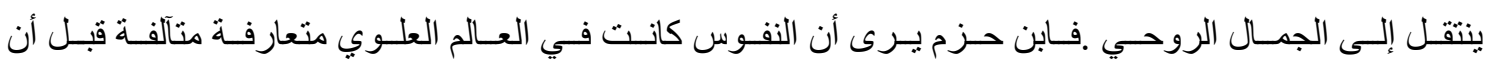
تنقسم باتصالها بالأجساد عندما هبطت إلى الأرض , وبسكنها لهذا الجسد فقدت الكثير من نور انيتها . شعر ابن حزم في كتاب طوق الحمامة الثـعر في كتـاب طـوق الحمامـة حديث طريـف يثيـر كثير اً مسن التأمسل ,و وهذا لـيس بشـيء غريـب لأنسه

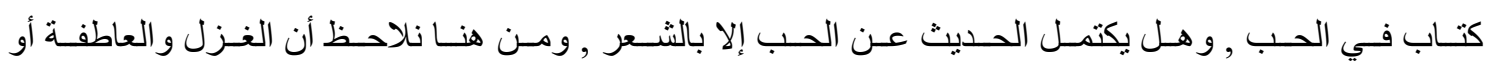

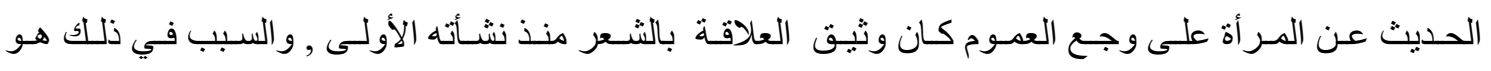



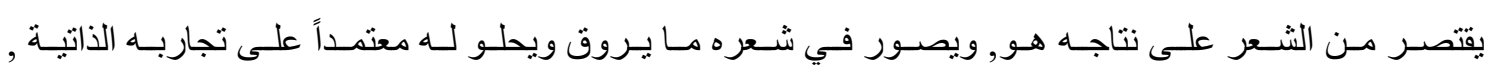



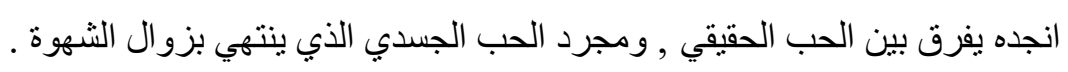

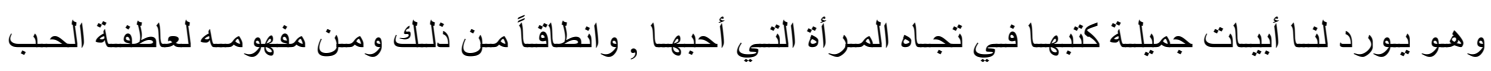
فإنه لا يجد حرجاً في التعبير عن صدق مشاعره و عو اطفه ولعل أروع شعر قاله في ذلك: 


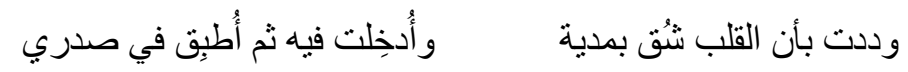

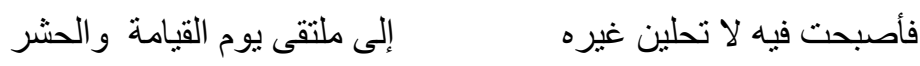

$$
\begin{aligned}
& \text { تعيثين فيه ما حييت فإن أمت سكنت شغاف القلب في ظلم القبر } 15
\end{aligned}
$$

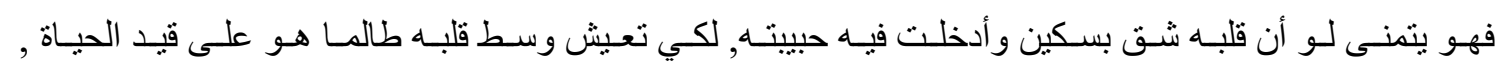
فإن مات سكنت قلبه وهو تحت لته التراب .



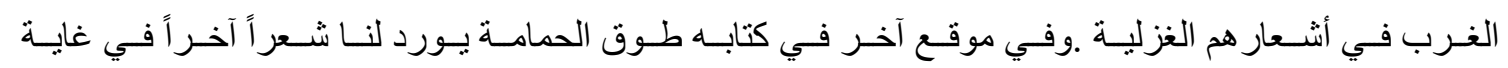

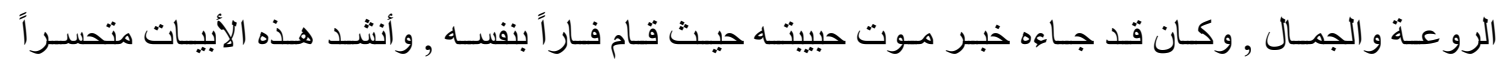

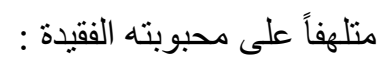

$$
\begin{aligned}
& \text { وددت بأن ظهر الأرض بطن وأن البطن صـار فيها ظهر ا } \\
& \text { و إني مت قبل ورود خطب أنى فأثتار في الأكباد جمر ا } \\
& \text { وأن دمي لمن قد بان غسل وأن ضلوع صدري كن قبر إ } 16
\end{aligned}
$$

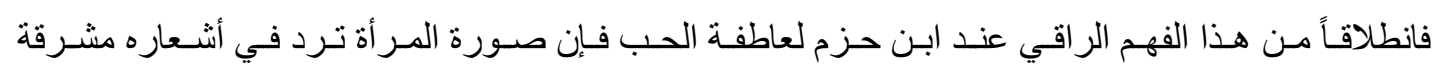

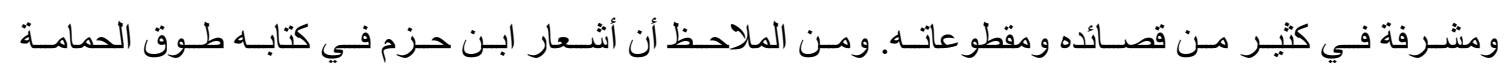
تمتاز بسهولة

الألفـاظ , وبعـدها عـن التعقبـد مـع عمـق المعنى , فهو أثـبه بكتـاب يعبر عمـا يـدور في داخلـه دون التـواء أو

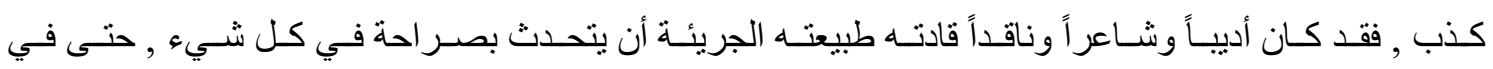



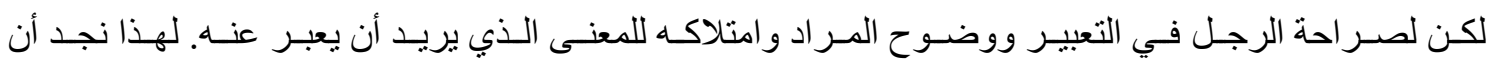

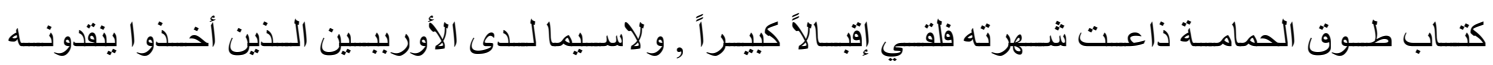

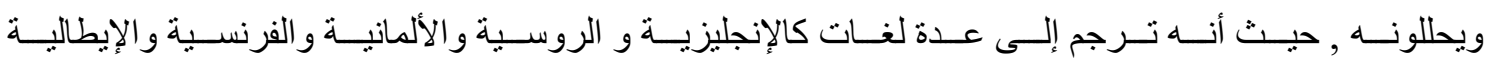

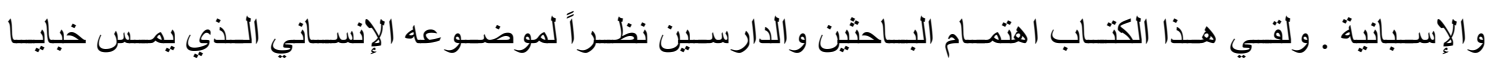
النفس في الحب و العاطفة وميول النفس الإنسانية.

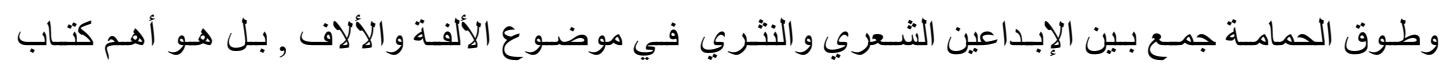

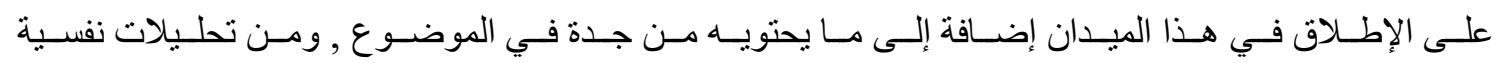

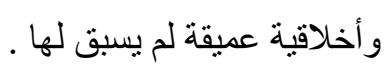

\footnotetext{
ابن حزم الأندلسي , رسائل ابن حزم , تح إحسان عباس , المؤسسة العربيه للادار و النشر , بيروت ,صيدا , ص184 15






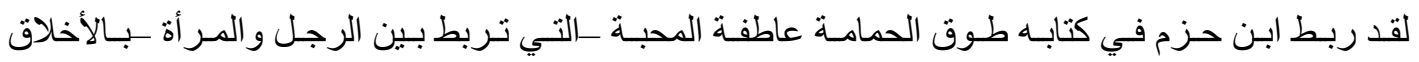

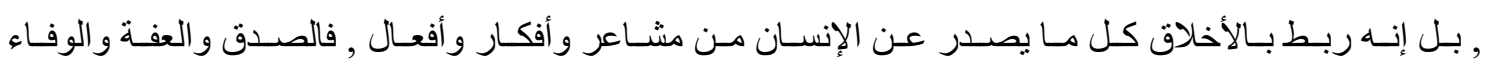

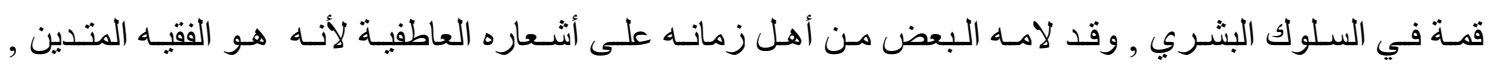

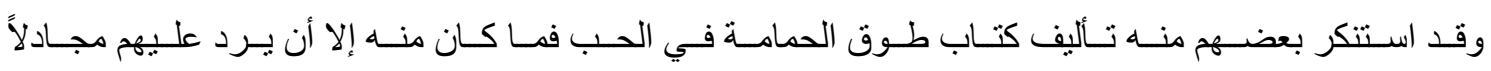

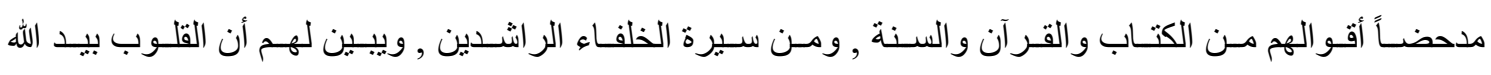



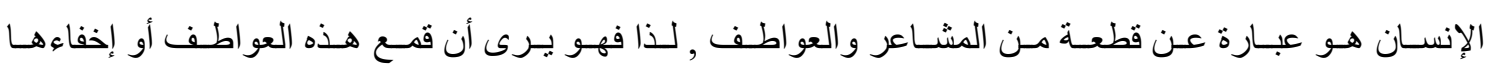

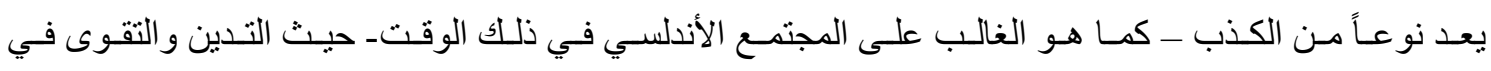

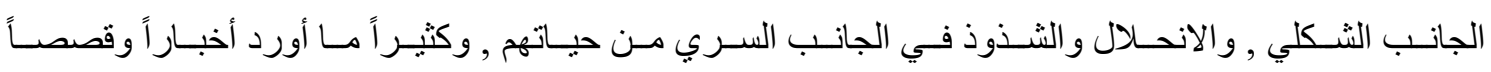

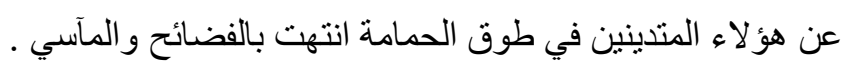

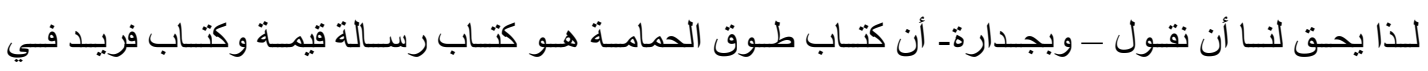

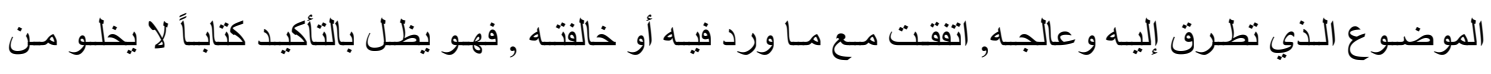

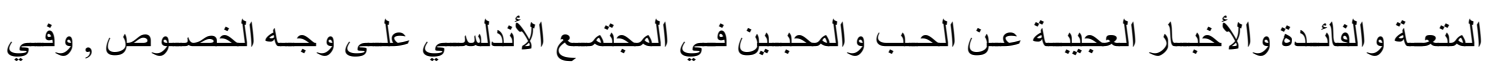
سائر الأزمنة والأمكنة على العموم.

الخاتمة


و الدارسة لنخصية ابن حزم ولكتابه طوق الحمامة في الألفة والألاف:

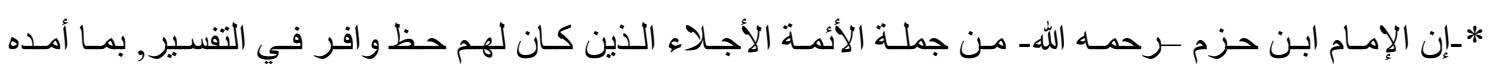



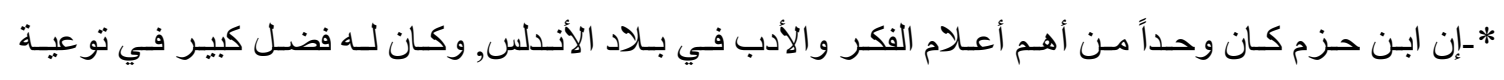
الناس وتبيان الحلال من الحرام , وتنومير عقول الناس.

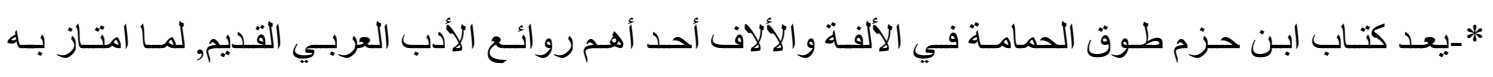

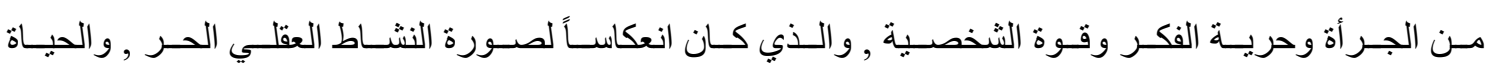

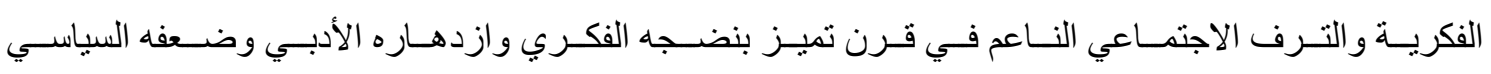
و وانحلاله الاجتماعي. * - التعرف على ابن حزم الأندلس كونه أول فقيه مسلم. 




- القرآن الكريم

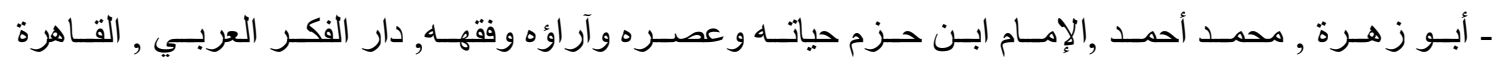

ـ ابن بشكول, الصلة في تاريخ أئمة الأندلس, مكتبة الحانجي , القاهرة,1994م ـ ابن كثير, البداية والنهاية , دار الفكر , بيروت, 1986


بيروت 1998م

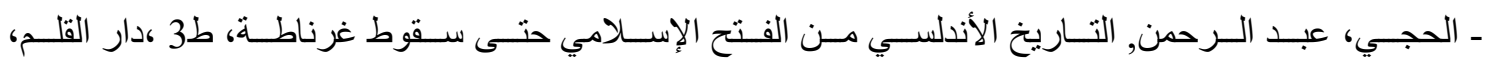
دمشن, , 1987 ـ الحموي , ياقوت, معجم البلدان , دار صادر , بيروت , ط2, ج2, 1995م

ـ الـرازي , مختـار الصـحاح , تحقيـق يوسـف الثـيخ محمـــ , المكتبـة العصـرية , الــار النموذجيـة , بيـروت , صيدا, ط5, 1999م ـ الزركلي, خير الدين, الأعلام, ,دار العلم للملابين ,ط15, 2002م

ـ الثـنتريني , علـي بـن بسـام ,الـذخيرة فـي محاسـن أهـل الجزيـرة , تحقيـق د. إحســان عبـاس , الـدار العربيــة للكتاب , ليبيا , تونس , ج1, ط1, 1981م ـ الضبي , أبو جعفر ربغية الملتمس في تاريخ رجال أهل الأندلس, مطبعة روخس المسيحية , 1884م

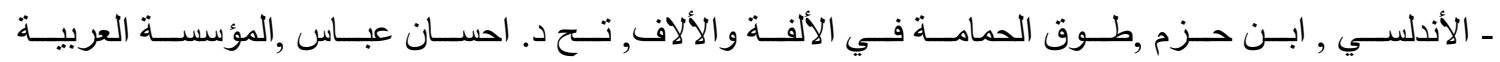

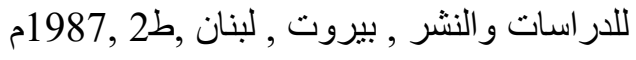
ـ الأندلسـي , ابـن حـزم ,رســائل ابـن حـزم , تـح إحســان عبـاس , المؤسســة العربيـة للـدار و النشـر , بيـروت ,

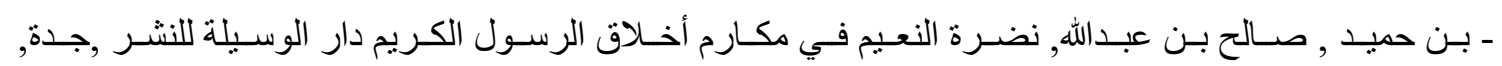
ط4, ج2 